\title{
ANALISIS KEPERCAYAAN, MOTIVASI DAN KEPUASAN ORANG TUA SISWA SMA KRISTEN PETRA 1 SURABAYA
}

\author{
Hatane Semuel $^{*}$, Vony Wijaya ${ }^{2}$ \\ ${ }^{1)}$ Faskultas Ekonomi Universitas Kristen Petra Surabaya \\ Email: samy@petra.ac.id \\ ${ }^{2)}$ SMA Kristen Petra I Surabaya \\ Email: vonywijaya1804@gmail.com \\ *Korespondensi
}

\begin{abstract}
Abstrak: Penelitian terhadap 91 orang tua siswa SMA Kristen Petra I Surabaya, 29 orang pria (32\%), dan 62 orang wanita (68\%), dengan status pekerjaan 22 orang (2,2\%) pegawai negeri sipil, 20 orang (22\%) pegawai swasta, 28 orang (30,8\%) wiraswasta, 37 orang $(40,7 \%)$ ibu rumah tangga, dan 4 orang $(4,4 \%)$ memiliki pekerjaan lainnya. Penelitian menguji pengaruh kepercayaan dan motivasi terhadap kepuasan orang tua siswa SMA Kristen Petra I Surabaya. Kepercayaan diukur dengan indikator: ability, benevolence, dan integrity; motivasi diukur dengan indikator: dorongan untuk melanjutkan pendidikan, kebutuhan untuk memiliki keahlian khusus, dan keinginan untuk meningkatkan kesejahteraan hidup, sedangkan kepuasan diukur dengan indikator: leadership. parental involvement, faith development, curriculum and instruction, communication, support service, facilities, serta environment. Kepercayaan sebagai variabel eksogenus, motivasi sebagai variabel mediasi, dan kepuasan sebagai variabel endogenus. Hasil penelitian menunjukan bahwa: (1) kepercayaan berpengaruh positif terhadap motivasi dan juga berpengaruh positif terhadap kepuasan orang tua; (2) motivasi berpengaruh positif terhadap kepuasan orang tua. Motivasi terbukti dapat menjadi mediasi antara kepercayaan terhadap kepuasan orang tua, sehingga secara total pengaruh kepercayaan terhadap kepuasan semakin kuat.
\end{abstract}

Kata kunci: Kepercayaan; motivasi; kepuasan; SMA Petra I.

\begin{abstract}
This study was done on 91 parents of high school students Kristen Petra I Surabaya, consisting of 29 men (32\%), and 62 women, (68\%), while the employment status there are 22 people (2.2\%) civil servants, private employees 20 people (22\%), 28 (30.8\%) were self-employed, housewives 37 people (40.7\%), and 4 (4.4\%) had other jobs. The study wanted to determine the effect of Confidence and Motivation on High School Students Parents were Kristen Petra I Surabaya. Trust is measured by indicators: ability, benevolence and integrity; motivation measured by indicators: the encouragement to continue their education, the need to have special skills, and the desire to improve the lives; while satisfaction is measured by indicators: leadership. parental involvement, faith development, curriculum and instruction, communication, support services, facilities and environment. Placing trust relationship between variables as exogenous variables and motivation as mediating variables, and satisfaction as an endogenous variable. The results showed that: (1) trust has positive effect on the motivation and the parent's satisfaction; (2) motivation has positive effect on the parent's satisfaction. Motivation is proven to be mediating between the trust to the parent's satisfaction, so that the total effect of the stronger trust to satisfaction.
\end{abstract}

Keywords: Trust; motivation; satisfaction; SMA Petra I

\section{PENDAHULUAN}

Menyusun strategi bersaing agar dapat tetap unggul di dalam persaingan, merupakan hal penting yang dapat dilakukan melalui peningkatan kualitas mutu layanan (Poole, M.S., Andrew H. Van de Ven., Kevin Doodle, and Michael E. Holmes, 2000). Bisnis pendidikan, seperti sekolah atau universitas, dapat bertahan, ketika mampu membuat para konsumen, seperti orang tua dan siswa; mengenal, menyukai dan memandang positif nama sekolah atau universitas, selalu dikaitkan dengan jumlah konsumen atau siswa yang lebih besar, (Dodds, Wiliam B., Monroe, Kent B., Grewal, Dhruv, 1991).
Keterlibatan orang tua membiayai kegiatan pendidikan anak, berimbas pada semakin besarnya tuntutan agar institusi pendidikan dapat memberikan layanan secara efektif dan efisien (Stodnick \& Rogers 2008). Salah satu langkah antisipatif yang digunakan untuk meningkatnya kesadaran orang tua terhadap pentingnya kualitas layanan pendidikan ialah dengan mengupayakan adanya peningkatan ketrampilan dan kecakapan staf yang terlibat dalam layanan, (Stodnick \& Rogers, 2008). Selain itu dengan melakukan evaluasi pelayanan pendidikan yang telah ditawarkan sebelumnya (Rahma \& Hartoyo, 2010). Evaluasi pelayanan pendidikan dilakukan dengan cara mengetahui tingkat kepuasan orangtua dengan mem- 
bandingkan kualitas fasilitas yang disediakan sekolah dengan yang diharapkan orang tua, (Rahma \& Hartoyo 2010).

Kepuasan merupakan bentuk perasaan yang timbul setelah membandingkan ekspektasi dengan kinerja sebuah barang atau jasa, (Kotler \& Keller, 2009). Terdapat beberapa faktor layanan institusi pendidikan yang dapat mempengaruhi kepuasan orang tua, diantaranya adanya keterlibatan orang tua dalam mendukung kegiatan belajar mengajar, kurikulum dan pendidikan agama yang diajarkan di sekolah, fasilitas pendidikan yang diperoleh peserta didik, lingkungan sekolah dan lingkungan sekitar sekolah, (Eastmo, 2008). Faktor lain yang dapat mempengaruhi kepuasan orang terhadap institusi pendidikan, adalah motivasi yang kemudian secara tidak langsung mampu meningkatkan kepercayaan, (White, 2015). Kepercayaan juga memiliki peran unggul dalam pembentukan loyalitas orang tua terhadap pusat penitipan anak, (Akbar \& Parvez 2009). Hal ini menjelaskan bahwa semakin orang tua percaya terhadap sebuah sekolah maka tingkat kepuasannya mengalami peningkatan. Selain itu desain kurikulum, prestasi siswa yang pernah dan yang masih menempuh pendidikan di sekolah, serta guru yang berkualitas, menjadi prioritas utama, (Kleitz, B., Weiher, G., Tedin, K., \& Matland, R. 2000).

Institusi Pendidikan Kristen Petra Surabaya adalah salah satu isntitusi yang menyelenggarakan pendidikan dari tingkat sekolah bermain anak balita sampai dengan sekolah menengah tingkat atas dengan konsep manajemen modern. Persaingan antar institusi pada level pendidikan sekolah menengah tingkat atas di kota Surabaya sangat ketat, sehingga strategi bersaing harus dilakukan dengan serius dengan tidak meninggalkan visi dan misi pendidikan institusi. Evaluasi terhadap kinerja layanan harus terus dilakukan, sehingga SMA Petra I sebagai salah satu SMA unggulan di Surabaya dipilih sebagai objek penelitian ini.

\section{KAJIAN PUSTAKA}

\section{Pemasaran Jasa}

Pemasaran jasa bersifat intangible dan immaterial karena produknya tidak kasat mata dan tidak dapat diraba.Produksi jasa dilakukan pada saat konsumen berhadapan dengan dan interaksi antara konsumen dengan produsen, (Rangkuti 2011).Karakteristik pelayanan meliputi intangibility, perishability, simultaneity, dan heterogenety. (Huo \& Hong, 2013).
Intangibility merupakan karakteristik fundamental dari fitur yang membedakan pelayanan dengan produk fisik.Jasa adalah suatu perbuatan, tindakan, pengalaman, proses, kinerja, atau usaha. Perishability, artinya tidak tahan lama, yang mengacu pada ketidakbisaannya untuk disimpan dan dialihkan. Simultaneity atau insparability yaitu kebersamaan yang melibatkan partisipasi pengguna. Jasa umumnya dijual terlebih dahulu, baru kemudian diproduksi dan dikonsumsi pada waktu dan tempat yang sama. Produksi dan konsumsi pelayanan adalah concurrent, yaitu terjadi pada saat dua pihak, pengguna maupun penyedia layanan berinteraksi. Heterogeneity, yang artinya berbeda atau variasi sesuai pengalaman.

Pada pemasaran jasa, kualitas layanan memegang peranan penting, pelanggan akan memiliki harapan atas suatu pelayanan dibandingkan dengan pelayanan yang duterima untuk menentukan terpenuhi atau tidaknya harapan atas pelayanan tersebut (Baker \& Saren, 2011).

\section{Parent's Satisfaction}

Secara umum, kepuasan merupakan perasaan senang atau kecewa individu yang timbul karena membandingkan kinerja yang dipersepsikan melalui produk atau jasa terhadap ekspektasi. Jika kinerja gagal memenuhi ekspektasi, maka pelanggan akan tidak puas. Jika kinerja sesuai ekspektasi, maka pelanggan akan puas, dan jika kinerja melebihi ekspektasi, maka pelanggan akan sangat puas atau senang (Kotler \& Keller, 2009).

Kepuasan konsumen yang tercipta, menunjukan adanya pengaruh antara keterlibatan konsumen dengan penyedia layanan (Khan 2012). Selain itu, kepuasan konsumen mengarah pada sudut pandang pengalaman konsumen. Konsumen melakukan penilaian, berdasarkan pengalamannya menggunakan produk atau jasa, (Irawan 2009). Terdapat sejumlah metode yang dapat digunakan untuk mengukur kepuasan pelanggan. Survei berkala dapat melacak kepuasan pelanggan secara langsung, serta perusahaan dapat mengamati tingkat kehilangan pelanggan dan menghubungi pelanggan yang berhenti membeli atau beralih ke pemasok lain (Kotler \& Keller, 2009).

Kepuasan orang tua terhadap sebuah sekolah merupakan salah satu bentuk komunikasi yang dilakukan sekolah terkait kinerjanya.dari sekolah. Kepuasan dapat tercipta melalui beberapa proses, salah satunya melalui the expectacy disconfirmation model, yakni kepuasan yang terbentuk akibat dari membandingkan harapan mengenai fungsi produk 
yang seharusnya dengan kinerja produk yang ditunjukkan, (Rahma \& Hartoyo, 2010). Selain itu, proses pembentukan juga dapat melalui equition theory, yaitu menganalisis kepuasan dengan membandingkan input dengan outcomes yang diterima oleh pelanggan, (Rahma \& Hartoyo 2010). Input yang dikeluarkan oleh pelanggan meliputi pencarian informasi, uang, waktu dan usaha yang diberikan, sedangkan outcomes yang diterima oleh pelanggan berupa manfaat dan kerugian setelah proses dari input yang telah diberikan oleh pelanggan (Rahma \& Hartoyo, 2010).

Kepuasan orang tua memiliki hubungan yang kuat dengan efektivitas sekolah dan prestasi siswa (Eastmo, 2008). Pengukuran kepuasan orang tua terhadap sebuah sekolah dapat melalui indikator berikut, yakni: Leadership, Parental involvement ,Faith development, Curriculum and instruction, Communication, Support service, Facilities, dan Environment.

\section{Kepercayaan}

Keyakinan sama dengan kepercayaan adalah kesediaan satu pihak untuk memercayai pihak lain, dan akan melakukan tindakan tertentu, (Mayer, R.C., Davis, J.H. \& Schooma, F.D. 1995). Keyakinan merupakan konstruk multidimensional yang kompleks serta dapat dipengaruhi dengan cara yang berbeda termasuk dalam suatu harapan bahwa pihak lain akan melakukan tindakan tertentu, Colquit, J.A., Scott, B.A. \& LePine, J.A., 2007).

Perilaku koneksitas yang terjadi antara perusahaan dan konsumen sering ditentukan oleh kepercayaan dan komitmen, (Morgan \& Hunt 1994). Kepercayaan didefinisikan sebagai keinginan untuk bergantung pada pertukaran mitra, (Moorman, C., Zaltman, G. \& Deshpande, R., 1992). Keyakinan seorang konsumen merupakan hal yang ingin diperoleh berbagai perusahaan, namun, keyakinan konsumen bukan hal yang mudah untuk diperoleh serta menanamkan pemikiran positif pada kognitif konsumen, (Harun, 2013). Konstruk multidimensional kepercayaan yang kompleks kemudian dapat dipengaruhi dengan cara berbeda dari rangsangan berbeda memiliki dimensi Ability, Benevolence, Integrity, dan Trustor, (Mayer, et al. 1995).

\section{Motivasi}

Motivasi adalah suatu keahlian, dalam mengarahkan pegawai dan organisasi agar mau bekerja secara berhasil, sehingga keinginan para pegawai dan tujuan organisasi tercapai secara bersama
(Hasibuan, 2000). Motivasi sebagai proses yang menjelaskan intensitas, arah, dan ketekunan seorang individu untuk mencapai tujuannya, pada umumnya berkaitan dengan usaha untuk mencapai apapun, serta dinyatakan dalam tiga elemen utama yaitu:.intensitas, arah, dan ketekunan, (Robbins SP, 2008). Intensitas berhubungan dengan seberapa giat seseorang berusaha, elemen ini merupakan elemen yang paling mendapatkan perhatian disetiap pembahasan mengenai motivasi. Namun, intensitas yang tinggi sepertinya tidak akan memberikan hasil prestasi kerja yang memuaskan kecuali upaya tersebut dikaitkan dengan arah yang akan menguntungkan organisasi. Motivasi merupakan suatu proses psikologis yang mencerminkan interaksi antar sikap, kebutuhan, persepsi, dan keputusan yang terjadi dalam diri seseorang (Saputra \& Hatane 2013).

\section{Pengaruh Kepercayaan terhadap Motivasi}

Kepercayaan adalah kesediaan satu pihak untuk memercayai pihak lain dan akan melakukan tindakan tertentu yang penting, (Mayer et al. 1995). Keyakinan konsumen merupakan hal yang ingin diperoleh berbagai perusahaan, yaitu hal positif dari sebuah merek produk atau jasa, (Mayer et al. 1995). Kepercayaan seseorang akan mendorong motivasi untuk melakukan pembelian dan menggunakan produk atau jasa tersebut, bahkan dapat melakukan pembelian ulang terhadap produk atau jasa tersebut (Omar, N.A., Muhamad Azrin Nazri, Nor Khaqlifah Abu, Zoharah Omar, 2009)

\section{Kepercayaan dan Parent's Satisfaction}

Perilaku keterhubungan yang terjadi antara perusahaan dan konsumen banyak ditentukan oleh kepercayaan dan komitmen (Morgan \& Hunt 1994). Kepercayaan pihak tertentu terhadap yang lain dalam melakukan hubungan transaksi berdasarkan suatu kepercayaan akan memenuhi segala kewajibannya secara baik sesuai dengan apa yang diharapkan (Juanita \& Lestari 2015). Kepercayaan adalah kesediaan atau kerelaan yang merupakan hasil dari sebuah keyakinan bahwa pihak yang terlibat dalam pertukaran akan memberikan kualitas yang konsisten, kejujuran, bertanggung jawab, ringan tangan dan berhati baik, dan dapat dicirikan oleh terpenuhinya kepuasan (Supriyadi \& Marlien, 2011). Kepercayaan seorang pelanggan terhadap sebuah institusi akan memiliki dampak positif terhadap kepuasan (Akbar \& 
Parvez 2009). Semakin orang tua percaya terhadap sebuah sekolah maka tingkat kepuasan akan mengalami peningkatan. Kondisi kepercayaan dari orang tua dapat terbentuk salah satunya berdasarkan pengalaman yang telah dirasakan (Akbar \& Parvez 2009; Omar et al. 2009). Kurangnya kepercayaan bisa menimbulkan ketidakpuasan dan menyebabkan kerusakan hubungan dengan pelanggan, (Graft, Raol, Roberts, Deborah, Guiot, Denis, 2011).

\section{Pengaruh Motivasi terhadap Parent's Satisfaction}

Motivasi merupakan proses yang menjelaskan intensitas, arah, dan ketekunan seorang individu untuk mencapai tujuannya (Robbins SP 2008). Motivasi yang ada pada individu akan mewujudkan suatu perilaku yang diarahkan pada tujuan mencapai kepuasan. Jadi dengan kata lain setiap perilaku/kegiatan konsumen diarahkan untuk memenuhi tujuan tertentu yang berkaitan dengan kebutuhan dalam memperoleh kepuasan. Ketika sebuah sekolah membangun metode pembelajaran yang efektif untuk mendorong motivasi belajar dari peserta didik, maka dengan sendirinya dapat meningkatkan motivasi orang tua untuk mendorong anaknya belajar (Rehman \& Haider 2013). Hal ini menunjukan bahwa ketika orang tua memiliki motivasi yang tinggi maka tingkat kepuasan terhadap pelayanan pendidikan yang disediakan sekolah akan mengalami peningkatan (Rehman \& Haider 2013).

\section{Hipotesis Penelitian}

Pendidikan bagi anak merupakan kewajiban orangtua yang harus ditunaikan agar anak dapat meraih masa depan yang lebih berkualitas. Pemilihan lembaga pendidikan menjadi krusial, ketika orangtua harus mengambil keputusan untuk mendaftarkan anaknya ke sekolah tertentu. Proses pemilihan sekolah ini merupakan tahapan yang melibatkan elemenelemen psikologis dan fisik yang harus dilalui oleh orangtua.

Beberapa hal yang dipertimbangkan sebelum mendaftarkan anaknya ke sekolah, di antaranya adalah sikap orangtua terhadap sekolah yang dipilih dan norma subyektif, dimana sikap orangtua dipengaruhi oleh persepsi (evaluasi), keyakinan, dan motivasi orangtua (Ajzen 2002). Berdasarkan hubungan antar variabel dan tinjauan pustaka yang telah dikemukakan pada bagian sebelumnya, maka hipotesis dan kerangka konseptual penelitian ini ialah sebagai berikut:

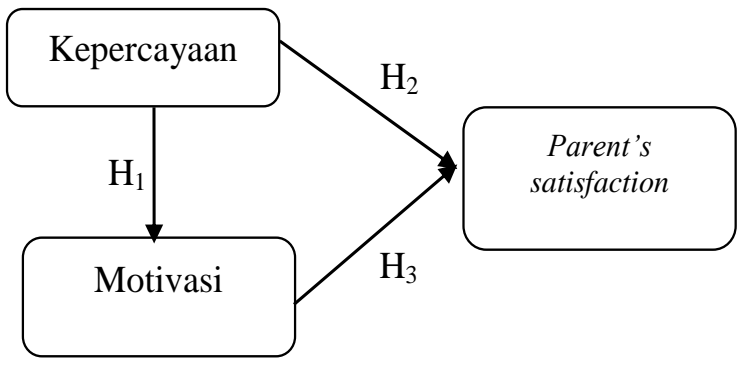

Gambar 1. Kerangka Hipotesis

Rumusan hipotesis dalam penelitian ini adalah:

H1: Kepercayaan Orang Tua akan sebuah sekolah memiliki pengaruh yang positif terhadap motivasi Orang Tua untuk mendaftarkan anaknya ke sekolah.

H2: Kepercayaan Orang Tua akan sebuah sekolah memiliki pengaruh yang positif terhadap Parent's satisfaction.

H3: Motivasi Orang Tua untuk mendaftarkan anaknya ke sekolah memiliki pengaruh yang positif terhadap Parent's satisfaction.

\section{METODE PENELITIAN}

Populasi dalam penelitian ini adalah orangtua peserta didik di SMA Kristen Petra 1 Surabaya dengan sampel untuk kelas X dan XI, perincian jumlah keseluruhan sebagai berikut:

- Siswa kelas X SMA Kristen Petra 1 Surabaya: 440 orang

- Siswa kelas XI SMA Kristen Petra 1 Surabaya: 480 orang

Teknik pengambilan sampel penelitian ini adalah nonprobability sampling, yaitu teknik sampling dimana anggota populasi tidak memiliki peluang yang sama untuk dipilih sebagai sampel (Jackson 2012). Jumlah sampel menggunakan rumus Slovin (Umar 2002), sebagai berikut:

Dimana:

$$
\mathrm{n}=\frac{\mathrm{N}}{\mathrm{N} \cdot \mathrm{d}^{2}+1}
$$

$\mathrm{n}$ : ukuran sampel

$\mathrm{N}$ : jumlah populasi yang diketahui

d : batas toleransi terhadap kesalahan pengambilan sampel karena ketidaktelitian, yaitu $10 \%$.

Sehingga, dari rumus tersebut diperoleh persamaan sebagai berikut:

$$
\begin{array}{ll}
\mathrm{n}=\frac{920}{920(0,01)^{2}+1} \mathrm{n}=\frac{920}{920(0,1)+1} \\
\mathrm{n}=\frac{920}{9,2+1} & \mathrm{n}=90,1960784
\end{array}
$$




\section{Uji Validitas dan Reliabilitas Instrumen}

Instrumen penelitian adalah kuesioner disusun dalam pernyataan tertutup, dengan menggunakan skala Likert. Rentang skala yang umum digunakan adalah rentang skala 5, yang terdiri atas skor 1, 2, 3, 4, dan 5, dimana skor 3 merupakan skor dengan posisi netral. Sementara 1, 2, 4, dan 5 merupakan skor ekstrem. Pemilihan Likert dengan rentang skala 5 ini didasarkan pada asumsi untuk menghindari respon bias dari masing-masing skor yang diberikan oleh responden, jika jarak skala terlalu dekat.

\section{Uji Validitas}

Pengujian validitas dalam penelitian ini menggunakan validitas isi, yaitu dengan mengukur sejauh mana isi instrumen pengukur mampu menwakili semua aspek yang dianggap sebagai aspek kerangka konsep. Validitas dilakukan dengan melihat korelasi pearson product moment (r) yang mengukur keeratan korelasi antara skor pertanyaan dengan jumlah skor dari variabel yang diamati. Sebuah item kuesioner dinyatakan valid jika nilai $r$ memiliki tingkat signifikansi kurang dari 5\% (Ghozali 2006). SPSS menyediakan vasilitas melalui koefisien Corrected ItemTotal Correlation, apabila nilai dari Corrected ItemTotal Correlation lebih dari 0,3, maka indikator atau istrumen pengukuran variabel valid.

\section{Uji Reliabilitas}

Uji reliabilitas digunakan untuk mengukur suatu kuesioner yang merupakan indikator dari variabel. Suatu kuesioner dikatakan reliabel apabila jawaban seorang sampel terhadap pernyataan bersifat konsisten atau stabil dari waktu ke waktu. Uji reliabilitas akan dilakukan dengan menggunakan uji statistik cronbach's alpha $(\alpha)$ dengan ketentuan bahwa variabel yang diteliti dinyatakan reliabel apabila nilai cronbach's alpha $(\alpha)$ adalah di atas 0,6 (Ghozali 2006).

\section{Uji Hipotesis}

Analisis model penelitian menggunakan SEM (Structural Equation Model) dan diselesaikan dengan Smart PLS, sehingga pengujian hipotesis disesuaikan dengan software ini. Pengujian hipotesis dalam penelitian ini dilakukan dengan melihat dari koefisien jalur yang ada dengan membandingkan antara nilai probabilitas 0,05 .

\section{ANALISIS DAN PEMBAHASAN}

Analisis data data dalam penelitian menggunakan Structural Equation Modelling (SEM) dengan software SmartPLS (Partial Least Square). Dimana PLS Path Modeling terdapat 2 model yaitu outer model dan inner model:

\section{Evaluasi Outer Model}

\section{Convergent Validity}

Convergent validity dari measurement model dengan indikator refleksif dapat dilihat dari korelasi antara score item/indikator dengan skor konstraknya. Indikator individu dianggap reliable jika memiliki nilai kolerasi diatas 0.70 . Namun demikian pada riset tahap pengembangan skala, loading 0.50 sampai 0.60 masih dapat diterima (Ghozali, 2006, p.40).Adapun hasil korelasi antara indikator dengan kontruknya seperti terlihat pada ouput Loading Factor seperti pada Tabel 1.

Tabel 1. Factor Loading

\begin{tabular}{|c|c|c|}
\hline Variabel & Indikator & $\begin{array}{l}\text { Loading } \\
\text { Factor }\end{array}$ \\
\hline \multirow[t]{10}{*}{$\begin{array}{l}\text { Parent's } \\
\text { satisfaction }\end{array}$} & $\begin{array}{l}\text { Saya puas dengan kinerja } \\
\text { pemimpin sekolah ini. }\end{array}$ & 0,659 \\
\hline & $\begin{array}{l}\text { Saya puas dengan kegiatan } \\
\text { parenting di sekolah ini. }\end{array}$ & 0,904 \\
\hline & $\begin{array}{l}\text { Saya puas dengan prestasi } \\
\text { sekolah ini. }\end{array}$ & 0,875 \\
\hline & $\begin{array}{l}\text { Saya puas dengan jenis ekstra } \\
\text { kurikuler yang diberikan di } \\
\text { sekolah ini. }\end{array}$ & 0,879 \\
\hline & $\begin{array}{l}\text { Kepuasan saya terhadap sekolah } \\
\text { ini sesuai dengan pengalaman } \\
\text { saya saat menyekolahkan anak } \\
\text { saya sebelumnya di sini. }\end{array}$ & 0,881 \\
\hline & $\begin{array}{l}\text { Saya puas dengan lokasi sekolah } \\
\text { ini dari jarak rumah saya. }\end{array}$ & 0,890 \\
\hline & $\begin{array}{l}\text { Saya puas dengan sistem } \\
\text { keamanan sekolah ini. }\end{array}$ & 0,890 \\
\hline & Saya puas dengan keadaan & 0,897 \\
\hline & $\begin{array}{l}\text { lingkungan sekitar sekolah ini. } \\
\text { Saya puas dengan keadaan } \\
\text { gedung sekolah ini. }\end{array}$ & 0,844 \\
\hline & $\begin{array}{l}\text { Saya puas dengan adanya ciri } \\
\text { khas keagamaan di sekolah ini. }\end{array}$ & 0,852 \\
\hline \multirow[t]{3}{*}{ Kepercayaan } & $\begin{array}{l}\text { Saya percaya sekolah ini } \\
\text { memiliki metode pembelajaran } \\
\text { yang baik. }\end{array}$ & 0,846 \\
\hline & $\begin{array}{l}\text { Saya percaya sekolah ini mampu } \\
\text { mendidik anak saya dengan baik. }\end{array}$ & 0,857 \\
\hline & $\begin{array}{l}\text { Saya percaya sekolah ini telah } \\
\text { didukung oleh sumber daya } \\
\text { manusia yang kompeten. }\end{array}$ & 0,844 \\
\hline \multirow[t]{3}{*}{ Motivasi } & $\begin{array}{l}\text { Saya ingin anak saya } \\
\text { mendapatkan pendidikan yang } \\
\text { terbaik di sekolah ini. }\end{array}$ & 0,858 \\
\hline & $\begin{array}{l}\text { Saya ingin anak saya mampu } \\
\text { mengembangkan keahliannya di } \\
\text { sekolah ini. }\end{array}$ & 0,883 \\
\hline & $\begin{array}{l}\text { Saya ingin anak saya memiliki } \\
\text { masa depan yang lebih baik } \\
\text { dengan bersekolah di sini. }\end{array}$ & 0,786 \\
\hline
\end{tabular}


Berdasarkan Tabel 1 diketahui bahwa variabel kepercayaan diukur dengan 3 dimensi pengukuran semuanya dinyatakan valid.Sama halnya variabel motivasi diukur dengan 3 dimensi pengukuran semuanya dinyatakan valid.Serta variabel Parent's satisfaction diukur dengan 10 dimensi pengukuran semuanya dinyatakan valid. Rata-rata dari masingmasing dimensi pengukuran memiliki nilai loading factor $>0,70$. Namun, terdapat satu dimensi pengukuran yang memiliki nilai loading factor $<0,70$. Apabila mengacu pernyatan Ghozali, (2006, p.40), loading 0.50 sampai 0.60 masih dapat diterima.

Pada Gambar 2 merupakan outer model dalam penelitian ini.

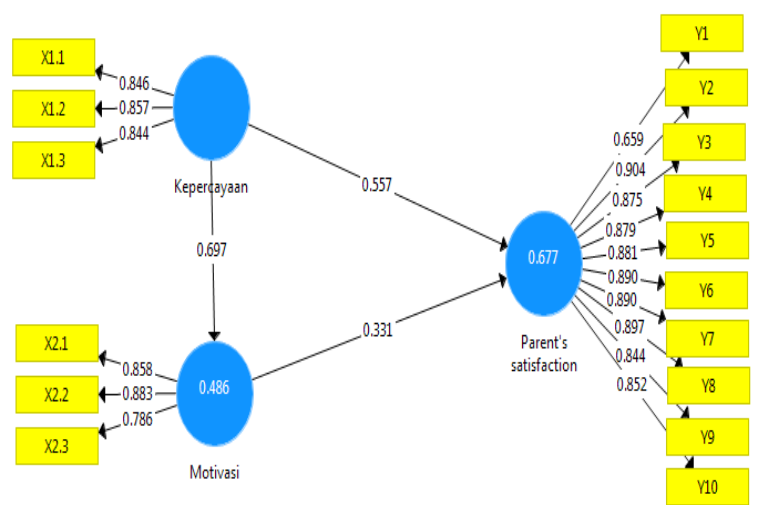

Gambar 2. Outer Model (PLS Alogaritm)

\section{Discriminant Validity}

Discriminant validity ditunjukkan Tabel 2.

Tabel 2. Cross Loading

\begin{tabular}{cccc}
\hline & \multicolumn{3}{c}{ Variabel } \\
\cline { 2 - 4 } Indikator & Kepercayaan & Motivasi & $\begin{array}{c}\text { Parent's } \\
\text { satisfaction }\end{array}$ \\
\hline X1.1 & 0,846 & 0,516 & 0,697 \\
X1.2 & 0,857 & 0,701 & 0,661 \\
X1.3 & 0,844 & 0,546 & 0,650 \\
X2.1 & 0,661 & 0,858 & 0,672 \\
X2.2 & 0,640 & 0,883 & 0,660 \\
X2.3 & 0,413 & 0,786 & 0,443 \\
Y1 & 0,658 & 0,594 & 0,659 \\
Y2 & 0,726 & 0,623 & 0,904 \\
Y3 & 0,583 & 0,613 & 0,875 \\
Y4 & 0,675 & 0,555 & 0,879 \\
Y5 & 0,723 & 0,579 & 0,881 \\
Y6 & 0,735 & 0,630 & 0,890 \\
Y7 & 0,677 & 0,582 & 0,890 \\
Y8 & 0,677 & 0,725 & 0,897 \\
Y9 & 0,643 & 0,637 & 0,844 \\
Y10 & 0,647 & 0,626 & 0,852 \\
\hline
\end{tabular}

Sumber: Hasil Regresi SmartPLS
Berdasarkan Tabel 2diketahui bahwa setiap blok indikator memiliki loading lebih tinggi untuk setiap variabel laten yang diukur dibanding dengan indikator untuk laten variabel lainnya. Artinya, indikatorindikator yang digunakan dalam penelitian ini telah memiliki discriminant validity yang baik dalam menyusun variabelnya masing-masing karena setiap indikatornya memiliki nilai diatas 0.5.hasil ini diperkuat dengan hasil analisis Average Variance Extracted (AVE) berikut.

\section{Average Variance Extracted (AVE)}

Tabel 3. AVE, Akar AVE, Korelasi AntarVariabel

\begin{tabular}{lccccc}
\hline \multicolumn{1}{c}{ Variabel } & AVE & $\begin{array}{c}\text { Akar } \\
\text { AVE }\end{array}$ & $\begin{array}{c}\text { Keper- } \\
\text { cayaan }\end{array}$ & $\begin{array}{c}\text { Moti- } \\
\text { vasi }\end{array}$ & $\begin{array}{c}\text { Parent's } \\
\text { satisfaction }\end{array}$ \\
\hline $\begin{array}{l}\text { Kepercayaan } \\
\text { Motivasi }\end{array}$ & 0,720 & 0,848 & 0,849 & & \\
$\begin{array}{l}\text { Parent's } \\
\text { satisfaction }\end{array}$ & 0,739 & 0,843 & 0,697 & 0,843 & \\
\hline
\end{tabular}

Berdasarkan Tabel 3 diketahui bahwa nilai AVE semua variabel $>0,5$. Diketahui juga bahwa semua nilai korelasi sebagian besar lebih kecil dari nilai akar AVE. Artinya, hasil tersebut dapat dinyatakan bahwa setiap variabel telah memiliki discriminant validity yang baik.

\section{Composite Reliability}

Composite reliability digunakan untuk mengukur konstruk atau internal consistency dan nilainya harus di atas 0,70 (Ghozali, 2008, p.25). Berikut tampilan Tabel 4. Tentang Composite Reliability.

Tabel 4. Composite Reliability

\begin{tabular}{lc}
\hline \multicolumn{1}{c}{ Variabel } & Composite Reliability \\
\hline Parent's satisfaction & 0,966 \\
Kepercayaan & 0,885 \\
Motivasi & 0,881 \\
\hline
\end{tabular}

Berdasarkan Tabel 4 diketahui bahwa nilai composite reliability semua variabel penelitian $>0,7$. Hasil ini menunjukkan bahwa masing-masing variabel telah memenuhi composite reliability sehingga dapat disimpulkan bahwa keseluruhan variabel memiliki level internalconsistency reliability yang tinggi. Artinya, secara komposit seluruh variabel memiliki konsistensi internal yang memadai dalam mengukur variabel laten/konstruk yang diukur sehingga dapat digunakan dalam analisis selanjutnya.

\section{Evaluasi Inner Model}

Pada evaluasi inner model dalam penelitian ini akan dijelaskan mengenai hasil path coefficient, uji goodness-of-fit, dan uji hipotesis: 


\section{Uji Path Coefficient}

Evaluasi path coefficient digunakan untuk menunjukkan seberapa kuat efek atau pengaruh variabel independen kepada variabel dependen. Hasil path coefficient lebih jelasnya dapat dilihat pada tabel berikut:

Tabel 5. Nilai Path Coefficient

\begin{tabular}{lcc}
\hline \multicolumn{1}{c}{ Variabel } & $\begin{array}{c}\text { Path } \\
\text { Coefficient }\end{array}$ & Signifikan \\
\hline $\begin{array}{l}\text { Kepercayaan }\left(\mathrm{X}_{1}\right) \rightarrow \text { motivasi }\left(\mathrm{X}_{2}\right) \\
\text { Kepercayaan }\left(\mathrm{X}_{1}\right) \rightarrow \text { parent's }\end{array}$ & 0,697 & 0,000 \\
$\quad$ satisfaction $(\mathrm{Y})$ & 0,557 & 0,000 \\
$\begin{array}{l}\text { Motivasi }\left(\mathrm{X}_{2}\right) \rightarrow \text { parent's satisfac- } \\
\text { tion }(\mathrm{Y})\end{array}$ & 0,331 & 0,000 \\
\hline
\end{tabular}

Berdasarkan tabel 5 dapat dijelaskan bahwa: (1) Kepercayaan $\left(\mathrm{X}_{1}\right)$ berpengaruh positif terhadap motivasi $\left(\mathrm{X}_{2}\right)$ dengan nilai path coefficient sebesar 0,697. (2) Kepercayaan $\left(X_{1}\right)$ berpengaruh positif terhadap parent's satisfaction $(\mathrm{Y})$ dengan nilai path coefficient sebesar 0,557. (3) Motivasi $\left(\mathrm{X}_{2}\right)$ berpengaruh positif terhadap parent's satisfaction $(\mathrm{Y})$ dengan nilai path coefficient sebesar 0,331. Dengan demikian, semakin tinggi kepercayaan dan motivasi maka akan semakin meningkatkan kepuasan dari orang tua.

\section{Uji Goodnes-Of-Fit}

Berdasarkan ouput PLS, pengujian Goodnes-OfFit dilihat dari perubahan nilai R-Square. Perubahan tersebut dapat digunakan untuk menilai pengaruh variabel laten independen tertentu terhadap variabel laten dependen apakah mempunyai pengaruh yang substantive.

Tabel 6. Nilai R-Square

\begin{tabular}{lcc}
\hline \multicolumn{1}{c}{ Variabel } & $\begin{array}{c}\text { Path } \\
\text { Coefficient }\end{array}$ & $\begin{array}{c}\text { Nilai R- } \\
\text { Square }\left(\mathrm{R}^{2}\right)\end{array}$ \\
\hline $\begin{array}{l}\text { Kepercayaan }\left(\mathrm{X}_{1}\right) \rightarrow \text { motivasi }\left(\mathrm{X}_{2}\right) \\
\text { Kepercayaan }\left(\mathrm{X}_{1}\right) \rightarrow \text { parent's satis- }\end{array}$ & 0,697 & 0,486 \\
$\quad$ faction $(\mathrm{Y})$ & & 0,357 \\
Motivasi $\left(\mathrm{X}_{2}\right) \rightarrow$ parent's satisfac- \\
$\quad$ tion $(\mathrm{Y})$
\end{tabular}

Berdasarkan Tabel 6 dapat diketahui bahwa nilai R-Square untuk kepercayaan terhadap motivasi adalah sebesar 0,486. Artinya, kontribusi yang diberikan oleh variabel kepercayaan terhadap variabel motivasisebesar 48,6\%. Nilai R-Square kepercayaan terhadap parent's satisfaction adalah sebesar 0,310. Artinya, kontribusi yang diberikan oleh variabel kepercayaan dalam menjelaskan perubahan yang terjadi pada variabel parent's satisfaction sebesar $31,0 \%$. Selanjutnya untuk nilai R-Square motivasi terhadap parent's satisfaction adalah sebesar 0,109. Artinya, kontribusi yang diberikan variabel motivasi dalam menjelaskan perubahan yang terjadi pada variabel parent's satisfaction sebesar 10,9\%.

Penilaian goodness of fit diketahui dari nilai QSquare. Nilai Q-Square memiliki arti yang sama dengan koefisien determinasi (R-Square) pada analisis regresi, dimana semakin tinggi Q-Square, maka model dapat dikatakan semakin fit dengan data. Adapun hasil perhitungan nilai nilai Q-Square adalah sebagai berikut:

$$
\begin{aligned}
\text { Q-Square } & =1-[(1-0,486) \times(1-0,310) \times(1-0,109)] \\
& =1-(0,514 \times 0,690 \times 0,891) \\
& =1-0,316 \\
& =0,68
\end{aligned}
$$

Hasil nilai $Q$-Square sebesar 0,68, menunjukan bahwa kemampuan memprediksi kepuasan orang tua siswa SMA Petra Kristen I Surabaya melalui kepercayaan dan motivasi menyekolahkan anaknya di sekolah ini adalah sebesar $68 \%$. Berdasarkan hasil tersebut, maka model pada penelitian ini dapat dinyatakan telah memiliki goodness of fit yang baik karena mampu menghasilkan kemampuan prediksi dari dalam model lebih dari $50 \%$.

\section{Uji Hipotesis}

Tabel 7. t Hitung dan P-Value

\begin{tabular}{clcc}
\hline Hipotesis & \multicolumn{1}{c}{ Pengaruh } & t-Hitung & P-Value \\
\hline H1 & Kepercayaan => Motivasi & 13,624 & 0,000 \\
H2 & $\begin{array}{l}\text { Kepercayaan =>parent's } \\
\text { satisfaction }\end{array}$ & 6,345 & 0,000 \\
H3 & $\begin{array}{l}\text { Motivasi =>parent's } \\
\text { satisfaction }\end{array}$ & 3,767 & 0,000 \\
\hline
\end{tabular}

Berdasarkan Tabel 7, maka diperoleh penjelasan sebagai berikut:

1. Kepercayaan memiliki pengaruh positif signifikan terhadap motivasi karena nilai t-hitung yang diperoleh sebesar 13,624 dengan $p$-value sebesar $0,000<0,05$, sehingga Hipotesis H1 dinyatakan diterima.

2. Kepercayaan memiliki pengaruh positif signifikan terhadap parent's satisfaction karena nilai t-hitung yang diperoleh sebesar 6,345 dengan $p$-value sebesar $0,000<0,05$, sehingga Hipotesis H2 dinyatakan diterima.

3. Motivasi memiliki pengaruh terhadap parent's satisfaction karena nilai t-hitung yang diperoleh 
pada adalah sebesar 3,767 dengan $p$-value sebesar $0,000<0,05$, sehingga Hipotesis H3 dinyatakan diterima.

\section{Pembahasan}

Hasil penelitian yang dilakukan kepada orang tua siswa di SMA Kristen Petra 1 mengenai parent's satisfaction memperoleh nilai top two boxes (53,975,9\%). Alasan paling kuat bagi orang tua merasa puas dengan SMA Kristen Petra 1 Surabaya ialah sekolah memiliki tenaga pengajar yang handal dengan persentase TTB sebesar 75,9\%, kemudian metode pembelajaran yang telah diterapkan di sekolah dengan persentase TTB sebesar 58,3\%, kemudian faktor keamanan yang dimiliki SMA Kristen Petra 1 Surabaya juga merupakan salah satu perihal yang menjadi alasan orang tua merasa puas dengan SMA Kristen Petra 1 Surabaya dengan persentase TTB sebesar 59,4\%.

Hasil penelitian yang dilakukan kepada orang tua siswa di SMA Kristen Petra 1 mengenai kepercayaan memperoleh nilai top two boxes $(63,8$ $71,5 \%$ ). Hasil ini menunjukkan bahwa orang tua memiliki kepercayaan terhadap sekolah yang berkualitas dikarenakan sekolah memiliki metode pembelajaran yang mampu menarik minat belajar, tenaga didik yang berkompeten, serta mampu mendidik anak dengan baik. Indikator dari variabel kepercayaan orang tua yang memiliki nilai TTB paling tinggi adalah orang tua mempercayakan anaknya ke sekolah yang memiliki tenaga didik yang berkompeten dengan nilai TTB sebesar 71,5\%.

Hasil penelitian yang dilakukan kepada orang tua siswa di SMA Kristen Petra 1 mengenai motivasi memperoleh nilai top two boxes $(67,1-75,9 \%)$. Hasil ini menunjukkan bahwa orangtua memiliki motivasi dalam mendaftarkan anaknya ke sekolah yang berkualitas agar anak memperoleh pendidikan yang terbaik, selain itu motivasi lainnya ialah agar anak dapat mengembangkan keahliannya, motivasi yang berikutnya ialah agar anak memiliki masa depan yang lebih baik dari orang tua. Indikator dari variabel motivasi yang memiliki nilai TTB paling tinggi adalah orang tua memiliki keinginan agar anak dapat mengembangkan potensi atau keahlian yang dimiliki dengan nilai TTB sebesar 75,9\%.

Berdasarkan pengujian hipotesis diperoleh hasil kepercayaan memiliki pengaruh positif signifikan terhadap motivasi, sehingga Hipotesis $\mathrm{H} 1$ dinyatakan diterima. Hal ini membuktikan bahwa kepercayaan mampu meningkatkan motivasi individu, motivasi yang dimaksud dapat berupa motivasi untuk melakukan melakukan tindakan tertentu yang penting bagi pihak yang memercayainya (Omar et al. 2009; Moslehpour \& Huyen 2014; Mayer, et al., 1995). Ketika orang tua siswa memiliki kepercayaan terhadap kompetensi yang dimiliki SMA Kristen Petra 1 Surabaya maka akan memberikan stimulus yang mampu memotivasi orang tua untuk menyekolahkan anaknya di SMA Kristen Petra 1 Surabaya.

Kepercayaan memiliki pengaruh positif signifikan terhadap parent's satisfaction, sehingga Hipotesis $\mathrm{H} 2$ dinyatakan diterima.Hal ini membuktikan bahwa apabila orang tua telah memiliki kepercayaan terhadap sebuah sekolah, orang tua dapat merasa tidak puas untuk menitipkan anaknya pada sekolah tersebut. Perilaku keterhubungan yang terjadi antara sebuah instansi, yang dalam penelitian ini merupakan instansi pendidikan, denga konsumen banyak ditentukan oleh kepercayaan dan komitmen (Morgan \& Hunt 1994). Hal ini dapat dikarenakan kepercayaan yang dibangun orang tua siswa terhadap sekolah bertolak belakang dengan yang diterima dan tidak sesuai ekspektasinya sehingga orang tua siswa menjadi tidak puas. Hasil penelitian ini didukung oleh penelitian yang telah dilakukan oleh Akbar dan Parvez (2009), Juanita \& Lestari (2015), dan (Eastmo 2008) membuktikan bahwa kepercayaan memiliki pengaruh positif signifikan terhadap parent's satisfaction. Artinya, semakin tinggi kepercayaan yang dimiliki orang tua maka akan meningkatkan kepuasan orang tua.

Motivasi memiliki pengaruh positif signifikan terhadap parent's satisfaction, sehingga Hipotesis H3 dinyatakan diterima. Hal ini membuktikan bahwa orang tua memiliki motivasi yang besar untuk mendaftarkan anaknya ke sekolah, maka orang tua akan memiliki rasa kepuasan yang lebih besar terhadap sekolah tersebut. Motivasi yang ada pada orang tua akan mewujudkan suatu perilaku orang tua untuk mendaftarkan anaknya ke sekolah (Robbins SP 2008). Hasil penelitian ini didukung oleh penelitian yang telah dilakukan oleh (Rehman \& Haider 2013) membuktikan bahwa motivasi memiliki pengaruh positif signifikan terhadap parent's satisfaction. Artinya, semakin tinggi motivasi yang dimiliki orang tua maka akan meningkatkan kepuasan orang tua.

Selain pengaruh langsung, hsil pengaruh tidak langsung kepercayaan terhadap parent's satisfaction melalui motivasi ditemukan memiliki nilai koefisien yang lebih kecil daripada pengaruh langsungnya.Hasil ini menjelaskan bahwa motivasi yang dimiliki orang tua cenderung melemahkan kepercayaan terhadap parent's satisfaction. Hal ini dapat terjadi karena seringkali orang tua membandingkan keunggulan yang dimiliki oleh suatu sekolah dengan sekolah lain (Krisno \& Samuel 2013). 


\section{KESIMPULAN DAN REKOMENDASI}

\section{Kesimpulan}

Berdasarkan rumusan masalah dan hasil penelitian, maka simpulan yang didapatkan dari penelitian ini adalah sebagai berikut:

1. Kepercayaan berpengaruh positif signifikan terhadap motivasi orang tua untuk mendaftarkan anaknya ke SMA Kristen Petra 1 Surabaya.

2. Kepercayaan berpengaruh positif signifikan terhadap kepuasan orang tua pada layanan pendidikan di SMA Kristen Petra 1 Surabaya.

3. Motivasi berpengaruh positif signifikan terhadap kepuasan orang tua pada layanan pendidikan di SMA Kristen Petra 1 Surabaya.

\section{Rekomendasi}

Berdasarkan kesimpulan dari hasil penelitian yang telah dilakukan di atas, maka saran yang dapat diajukan peneliti adalah sebagai berikut:

1. Bagi SMA Kristen Petra 1 Surabaya hendaknya: (1) dapat melakukan inovasi terkait metode pembelajaran yang diterapkan pada siswa; (2) dapat meningkatkan frekuensi mengikuti kompetisi baik yang bersifat akademik maupun non- akademik dengan tujuan mendapatkan prestasi sehingga dapat meningkatkan dorongan kepada orang tua siswa ketika menyekolahkan anaknya di SMA Kristen Petra 1 bertujuan mendapatkan pendidikkan terbaik; (3) dapat meningkatkan keragaman jenis ekstrakurikuler yang ada di sekolah, sehingga siswa dapat menyalurkan minat dan bakatnya pada kegiatan ekstrakurikuler.

2. Bagi Orang Tua, diharapkan (1) mampu mempertimbangkan segala aspek mengenai sekolah tempat anak mengenyam pendidikan ke jenjang yang lebih tinggi, baik dari aspek lingkungan, akademis dan infrastruktur (2) mencari info selengkapnya sebelum memutuskan untuk memilih sekolah yang cocok bagi putra putri mereka.

3. Bagi Penelitian Selanjutnya, diharapkan bisa menggunakan variabel lain diluar variabel yang telah digunakan dalam penelitian ini, seperti kualitas layanan, biaya pendidikan, dan promosi, agar hasil yang didapat lebih beragam dan berkontribusi bagi pengelola SMA Kristen Petra 1 Surabaya untuk merumuskan strategi dalam mendatangkan siswa.

\section{DAFTAR PUSTAKA}

Ajzen, I. (2002). Perceived Behavioral Control, SelfEfficacy, Locus of Control, and the Theory of Planned Behavior1. Journal of Applied Social Psychology, 80(6), pp.2918-2940.
Akbar, M.M. \& Parvez, N. (2009). Impact of service quality, trust, and customer satisfaction on customers loyalty. ABAC Journal, 29(1), pp.24-38. Available at: http://www.journal.au.edu/abac_ journal/2009/jan09/article02_JanApr2009.pdf.

Aryani, D. \& Rosinta, F. (2010). Pengaruh Kualitas Layanan terhadap Kepuasan Pelanggan dalam Membentuk Loyalitas Pelanggan. Jurnal Ilmu Administrasi dan Organisasi, 17(2), pp.114-126.

Baker, Michael, J., Saren, Michael. (2011). Marketing: Theory A Student Text. London: SAGE Publication.

Colquitt, J.A., Scott, B.A. \& LePine, J.A. (2007). Trust, trustworthiness, and trust propensity: A meta-analytic test of their unique relationships with risk taking and job performance. Journal of Applied Psychology, 92(4), pp.909-927.

Doods, W.B., Monroe, K.B. \& Grewal, D. (1991). Effect of Price, Brand and Store Information on Buyers Product Evaluation.Journal of Marketing Research, Vol. XXVII(June), pp.1-194

Eastmo, D.K. (2008). parents perceptions of educational services provided by the rapid city catholic school system. Dissertation.

Ghozali, I. (2006). Statistik Nonparametrik, Semarang: Badan Penerbit Universitas Diponegoro.

Graf, Raoul, Roberts, Deborah., Guiot, Denis. (2011). Trust or Satisfaction in a Relational Approach: The Case of Financial Institutions and HighTech Firms. Innovative Marketing, Vol. 7, Issue 4, 2011.

Harun, H.I. (2013). Hubungan Antara Kualitas Pelayanan Dengan Kepuasan Konsumen Pada Mahasiswa Pengguna Game Pointblank. EMPATHY Jurnal Fakultas Psikologi, 1(0274), pp.1689-1699.

Hasibuan. (2000). Organisasi dan Motivasi. Jakarta: Bumi Aksara.

Huo, Jiazhen \& Zhisheng Hong. (2013). Service Science in China. Heidelberg: Springer-Verlag Berlin Heidelberg.

Irawan, H. (2009). 10 Prinsip Kepuasan Pelanggan, Jakarta: PT ELex Media Komputindo.

Jackson, S. (2012). Research Methods and Statistics: A Critical Thinking Approach. Belmont.

Juanita, H.A. \& Lestari, U.P. (2015). Tingkat Kepercayaan Konsumen dan Pemanfaatan E-Marketing Terhadap Keputusan Pembelian Konsumen Produk E - Ticket Pesawat Di Octopus Travel Surabaya. Ebis, 7.

Khan, I. (2012). Impact of Customers Satisfaction And Customers Retention on Customer Loyalty. International Journal of Scientific \& Technology Research, 1(2), pp.106-110. 
Kleitz, B., Weiher, G., Tedin, K., \& Matland, R. (2000). Choice, charter schools, and household preferences. Social science quarterly, (846-854).

Kotler, P. \& Keller, K.L. (2009).Manajemen PemasaranKetiga., Jakarta: Erlangga.

Mayer, R.C., Davis, J.H. \& Schoorman, F.D. (1995). An Integrative Model of Organizational Trust. Source: The Academy of Management Review, 20(3), pp.709-734.

Moorman, C., Zaltman, G. \& Deshpande, R. (1992). Relationships Between Providers and Users of Market Research: The Dynamics of Trust Within and Between Organizations. Journal of Marketing Research (JMR), 29(3), pp.314-328.

Morgan, R.M. \& Hunt, S.D. (1994). The commitment-trust theory of relationship marketing. the journal of marketing, pp.20-38.

Moslehpour, M. \& Huyen, N.T. Le. (2014). The Influence of Perceived Brand Quality and Perceived Brand Prestige on Purchase Likelihood of iPhone and HTC Mobile Phone in Taiwan. Research in Business and Management, 1(1), p.62.

Omar, N.A. Muhamad Azrin Nazri, Nor Khalidah Abu, Zoharah Omar, (2009). Parents' Perceived Service Quality, Satisfaction and Trust of a Childcare Centre: Implication on Loyalty, 5(5), pp.299-314.

Poole, M.S, Andrew H. Van de Ven, Kevin Dooley, and Michael E. Holmes, (2000). Organizational change and innovation processes: Theory and methods for research, New York: Oxford University Press.
Rahma, A. \& Hartoyo.(2010). Pengaruh karakteristik orangtua dan sekolah terhadap tingkat kepuasan pelayanan pendidikan dasar, 3(2), pp.164-172.

Rangkuti, Freddy. (2011). Measuring Customer Satisfaction: Teknik Mengukur dan Strategi Meningkatkan Kepuasan Pelanggan. Jakarta: PT Gramedia Pustaka Utama.

Rehman, A. \& Haider, K. (2013). The Impact of Motivation on Learning of Secondary School Students in karachi: An Analytical Study. Educational Research International, 2(2), pp.139-147.

Robbins S.P., dan J. (2008). Perilaku organisasi, Jakarta: Salemba Empat.

Saputra, R. \& Hatane, S. (2013). Analisa Pengaruh Motivasi, Persepsi, Sikap Konsumen Terhadap Keputusan Pembelian Mobil Daihatsu Xenia di Sidoarjo. Manajemen Pemasaran, 1(1), pp.1-12.

Stodnick, M. \& Rogers, P. (2008).Using SERVQUAL to Measure the Quality of the Classroom Experience.Decision Sciences Journal of Innovative Education, 6(1), pp.115-133.

Sudaryana, A. (2014). Memahami Motivasi Dalam Proses Keputusan Pembelian Konsumen, pp. 456-463.

Supriyadi, Marlien. (2011). Analisis Kepercayaan, Citra Merek dan Kualitas Layanan Terhadap Loyalitas Pelanggan di Mediasi Kepuasan Pelanggan. Prosiding Seminar Nasional Multi Disiplin Ilmu \& Call For Papers Unisbank, 2011.

Umar, H. (2002). Metode Riset Bisnis. Jakarta: PT. Gramedia.

White, Christopher. (2015). The Impact of Motivation on Customer Satisfaction Formation: A self determination perspective. European Journal of Marketing, Vol. 49, Issue11. 